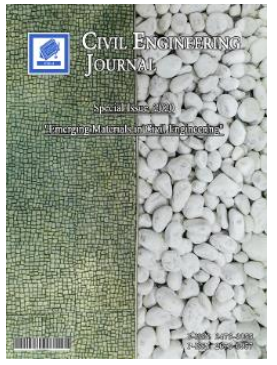

\title{
Pushover Response of Multi Degree of Freedom Steel Frames
}

\author{
Tayyab Naqash ${ }^{a^{*}}$ \\ ${ }^{a}$ Assistant Professor, Civil Engineering Department, Faculty of Engineering, Islamic University Madinah, Medina, Saudi Arabia.
}

Received 11 September 2020; Accepted 03 December 2020

\begin{abstract}
Seismic codes use the behaviour factor to consider the ductility and the structure's non-linearity to improve the system's overall performance. Generally, Steel moment-resisting frames are characterized by a relatively high period showing high deformability and, foreseen that with stringent damageability criteria, the adopted behaviour factor might not optimally be utilized for achieving better performance of the frames. The design is generally governed by stiffness, leaving behind a complex structural system where the capacity design rules are disturbed and therefore necessitates to relax the drift limits for such frames. Given this and with extensive parametric analysis, the current paper aims to examine the behaviour factor of steel Moment Resisting Frames (MRFs). The parametric analysis has been conducted on rigid steel MRFs of 9, 7, and 5 storeys with bay 4 different bay widths of $9.15 \mathrm{~m}, 7.63 \mathrm{~m}, 6.54 \mathrm{~m}$, and $5.08 \mathrm{~m}$. Perimeter frame configuration has been designed using 4 different behaviour factors $(q=6.5,4,3$, and 2$)$ for a total number of 144 cases. Static nonlinear analysis has been conducted, and consequently, the behaviour factors have been examined. It has been observed that compatibility is required while choosing the drift limit for an assumed ductility class of the code.
\end{abstract}

Keywords: Parametric Analysis; Steel Structures; Seismic Codes; Damageability; Ductility Classes; Nonlinear Analysis.

\section{Introduction}

The empirical factors (response modification factor or behaviour factor) given by the seismic codes intend to account for the ductility of the structural system. The concept that well-detailed seismic framing systems could sustain large inelastic deformations (ductile behaviour) without collapse and dissipative zones must exhibit wide and stable hysteresis loops. Many codes, such as the National Building Code of Canada and the New Zealand Earthquake Load Standard, explicitly recognized reserve strength by providing an overstrength modification factor. Other codes, such as the ASCE, International Building Code, and Australian Earthquake Standard, use composite reduction factor to account for both overstrength and ductility. Many sources of overstrength can be easily identified, but not all can be readily quantified.

Many researchers investigated these factors, such as Uang (1991) [1], who established R (or Rw) and Cd factors for building seismic provisions. Humar and Rahgozar (2000) [2] assessed the extent of reserve strength attributable to redistribution in steel frames. Most recently, design procedure combining the benefits of the Performance-Based Plastic Design approach with a rigorous accounting of second-order effects is proposed in Dell'Aglio et al. (2019) study [3]. Kappos (1999) [4] studied the evaluation of behaviour factors based on ductility and overstrength. Balendra and Huang studied overstrength and ductility factors for steel frames designed according to BS 5950. Several researchers examined the force reduction factors, providing detailed discussions and improvements on the ductility reduction factors for example, Castiglioni and Zambrano (2010) used the damage accumulation approach to determine

* Corresponding author: tayyab@iu.edu

http://dx.doi.org/10.28991/cej-2020-SP(EMCE)-08

(C) 2020 by the authors. Licensee C.E.J, Tehran, Iran. This article is an open access article distributed under the terms and conditions of the Creative Commons Attribution (CC-BY) license (http://creativecommons.org/licenses/by/4.0/). 
the behaviour factor of steel moment-resisting frames [5]. Many studies discusses the influence of the overstrength factor on the performance of structures designed according to the codified formulations, such as Sanchez-Ricart and Plumier (2008) [6] investigated overstrength factors for frames, highlighting the concept of capacity design. They performed a parametric study on 13,608 ductile moment-resisting steel frames designed according to Eurocodes 3 and 8. Fathi et al. (2006) [7] reviewed methods for evaluating behaviour factors, modifications of behaviour factor are indicated for multi-degree-of-freedom moment resisting steel frames.

Further, necessary modifications are made for determining the behaviour factor of frames involving the period and the base shear distribution factor for a given earthquake loading. Gioncu and Mazzolani (2013) [8] studied the ductility and seismic response of framed structures. Elghazouli (2009) [9] extensively contributed to assessing European seismic design procedures and philosophies for several lateral load resisting systems, especially concerning momentresisting frames due to their paramount inelastic behaviour [10]. This paper necessitates the examination of the behaviour factor once the capacity design rules are fulfilled. In the here designed cases, it has been noticed that the damageability rules of the frames are mostly not compatible with the ductility classes.

The current paper is organized into eight sections. This section of introduction is followed by research methodology, where the concept of the behaviour factor and ductility is presented. Section 3 presents the design criteria followed by the case study, modelling and nonlinear analysis. Section 7 presents results related to ductility and behaviour factor, and finally, the conclusions are drawn in section 8 . At the end of the paper nomenclatures of different variables used is also provided.

\section{Inelastic Behaviour}

The ductility factor theory relates the q-factor and other parameters for steel structures having period $>0.5 \mathrm{sec}$; it is used to interpret the results of inelastic dynamic analysis. In the first case, i.e., for relations obtained from simplified models, the hypothesis of the so-called 'structural regularity' is required, excluding closely spaced modes, torsional effects, and cases in which the structure cannot be modelled two-dimensional. These relations are also deduced for a global-type mechanism, leaving for a second phase, i.e., analyzing effects due to undesirable collapse mechanisms. This method can be illustrated with the aid of Figure 1. In this method, $q$ is derived from a series of dynamic inelastic analyses, for which the peak ground acceleration is increased systematically. The ratios $a / a_{d}$ and $\delta / \delta_{d}$ are computed at each step, where $a_{d}$ and $\delta_{d}$ are, respectively, the design acceleration and the corresponding maximum displacement evaluated employing a first-order elastic analysis.

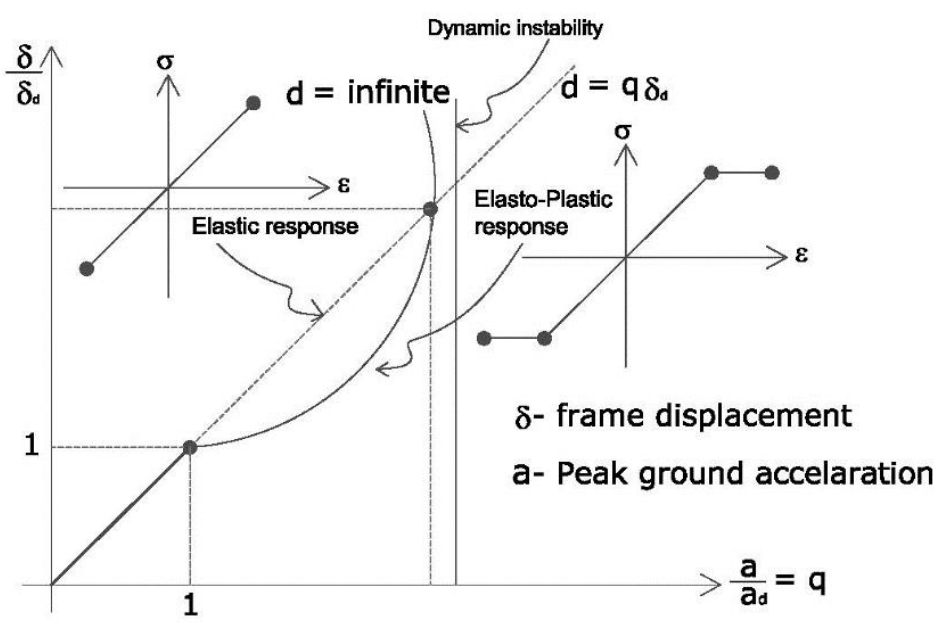

Figure 1. Evaluating of behaviour factor based on ductility (Ballio and Setti)

The design based on the elastic spectrum is valid until $\delta / \delta_{d}$ is less than $a / a_{d}$; therefore, the maximum value which can be assigned to the $q$ factor is given by the intersection between the curve for $\delta / \delta d$ and the value for $a / a_{d}$ derived from the dynamic inelastic analysis and purely elastic model. In this method, after reaching the point of first yielding in the frame, the value of $\delta / \delta_{d}$ should be less than $a / a_{d}$ to ensure that the rate of increase in the frame displacement is less than the increase rate of the ground acceleration. However, in most practical frames, the opposite is the case, and for this reason, this method is not suitable for many standard frames.

Methods based on the dynamic inelastic response of SDOF (Single Degree of Freedom) systems belonging to the second group require global collapse mechanisms and structural regularity. However, the research on inelastic spectra is strictly applicable to SDOF systems only. Its use has been extended to multi-degree of freedom systems as the extension derives from several parameters necessary to describe the pattern of yielding of multi-story frames. While a 
single parameter, such as the required global ductility, can be sufficient to characterize the SDOF response, in the case of MDOF systems, different patterns of yielding could correspond to the same maximum inelastic displacement. Furthermore, the vibration and participation factor of the 'fundamental-mode' is increased due to inelastic deformations. Moreover, when the structure becomes inelastic, the axial forces in the exterior columns can exceed the values predicted by modal analysis and inelastic spectra, leading to reduced plastic moment capacity and an increase of required ductility. It is useful to note that the ductility factor theory's validity range has been obtained from the analysis of SDOF systems.

Among the methods based on inelastic Single-Degree-Of-Freedom (SDOF) systems, Newmark and Hall (1969) are worth mentioning because it is the first and best-known method of this group. Figure 2 shows how to obtain the inelastic design response spectrum (IDRS) starting from a linear elastic design response spectrum (LEDRS) using the ductility factor $\mu$ [11]. However, there have been suggestions that by using this approach for Multi-Degree-OfFreedom (MDOF) systems, q can be overestimated by a factor of two in some cases [12].
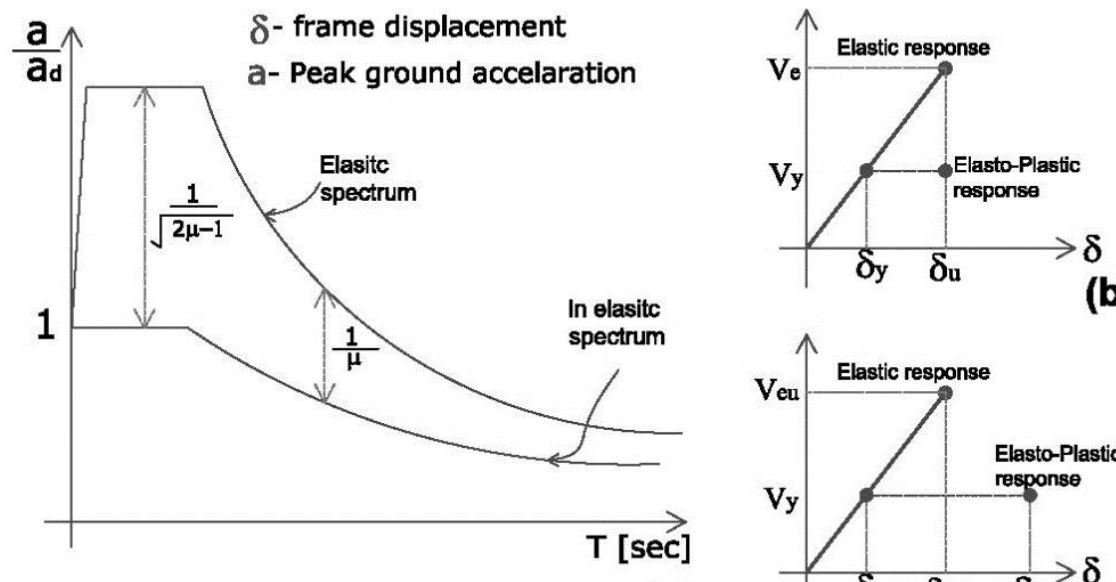

(a)

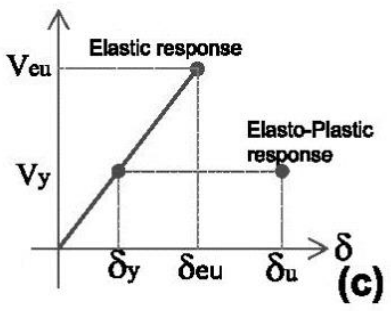

Figure 2. (a) Evaluating q based on SDOF systems; (b) Ductility factor theory; and (c) Equivalence energy theory

Finally, the energy approach methods are an extension of Housner's methodology developed in 1956 [13, 14] and do not require structural regularity and global mechanism hypotheses. In this approach, the complex evolution of the seismic motion of a structure must be considered. A basic approach divides the seismic motion of the structure into a series of simplified cycles of energy exchanges. Each cycle is composed of an initial phase during which kinetic energy is stored, and there is a gradual increase of elastic oscillations and the next phase during which the energy accumulated in the first phase is transformed into elastic-plastic work. The "q" factor is then defined by Equation 1.

$q=\left(\frac{w_{\mu}}{w_{y}}\right)^{1 / 2}$

This method has been applied for single-degree-of-freedom systems and not for multi-degree-of-freedom frames since it is impossible to combine the stored energies for various degrees of freedom. A different simplification of the energy method attempts to account for damage distribution. In this method, the earthquake input energy is compared with the steel structure's capacity for dissipating energy under the design earthquake. Evaluation of the earthquakeresisting capacity must be applied to each story. Consequently, the value of the $\mathrm{q}$ factor for the structure is the minimum value from the overall storeys. Although the method applies to irregular frames, evaluating the required parameters means that it is not a practical method yet [15].

\section{Design Criterion}

The nonlinear dynamic analysis of a structure requires much computational effort; contrarily, elastic analysis causes a considerable cost to the structure. Therefore, for stable structures, seismic codes suggest using a reduced spectrum to estimate lateral forces except for significant structures that require no damage under strong earthquakes. In US codes; UBC (1997), AISC (2010), ASCE (2017) [16-18], the response modification factor (R) is usually employed to account for the so-called in-elastic response of the framing system; this is referred as behaviour factor (q) in Eurocode 8. These empirical factors ( $\mathrm{R}$ or $\mathrm{q}$ ) are used to reduce the code specified elastic spectrum and therefore intend to account for the damping, structural overstrength, and the structural system's inherent ductility. The concept of these factors ( $\mathrm{R}$ or $\mathrm{q}$ ) is proposed based on the postulate that well-detailed seismic framing systems could sustain large in-elastic deformations without collapse (ductile behaviour) and develop lateral strengths above their design 
strength (often termed reserve overstrength). Therefore, the spectrum's amount of reduction depends on the overstrength, reserve, overstrength, and ductility of the structure. When using the provisions of Eurocodes $[6,19,20]$, primary beams are designed to satisfy both ultimate and serviceability limit states.

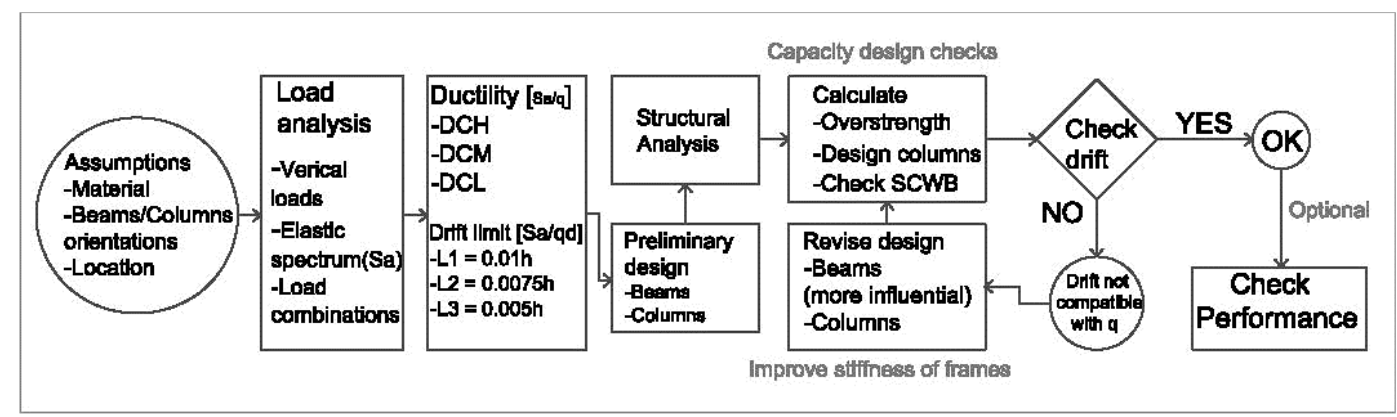

Figure 3. Flowchart following Eurocodes prescription for the capacity design of MRFs

The primary beams are initially designed for gravity loads and then checked regarding the seismic loading condition. In the design of primary beams, the overstrength is calculated, which generally is employed to dimension the column profiles. Column members are designed both for the ultimate limit state and for seismic conditions according to the capacity design approach of Eurocode 8 using the overstrength factor. Once the capacity design checks are satisfied, the damageability criterion needs to be checked in terms of inter-story drift limitations. These checks often result to be very stringent, and the members (beams cross-sections and column cross-sections) need to be revised to satisfy the damageability criteria. Since beams are assumed to be more influential than columns for improving the frame's lateral stiffness and consequently satisfying the inter-story drift criterion, it originates from the revision of the capacity design rules to great extents. These beam resizing iterate the design due to overstrength calculation, while the ductility class usually remains fixed, causing the reduction of the reserve overstrength. This process is repeated until both strength and stiffness checks are satisfied with several iterations. The flowchart shows this complete process in Figure 3.

\section{Case Study}

Frames comprised of 9,7 , and 5 storeys regular buildings with different spans $(9.15 \mathrm{~m}, 7.63 \mathrm{~m}, 6.54 \mathrm{~m}$, and 5.08 $\mathrm{m}$ ) have been studied to assess the behaviour factor of Eurocode 8. The building plan is considered to have perimeter steel MRFs (perimeter configuration). For idealization, a typical floor plan of the building with 5 bays is shown in Figure $4 \mathrm{a}$ and its elevation for 9 storeys in Figure $4 \mathrm{~b}$.

The inter-storey height is $4 \mathrm{~m}$, giving rise to an overall height of $36 \mathrm{~m}, 28 \mathrm{~m}$, and $20 \mathrm{~m}$ for 9,7 , and 5 storeys frames, respectively. The connections of the examined frames are assumed fully rigid; therefore, their influences are beyond the current paper's scope.
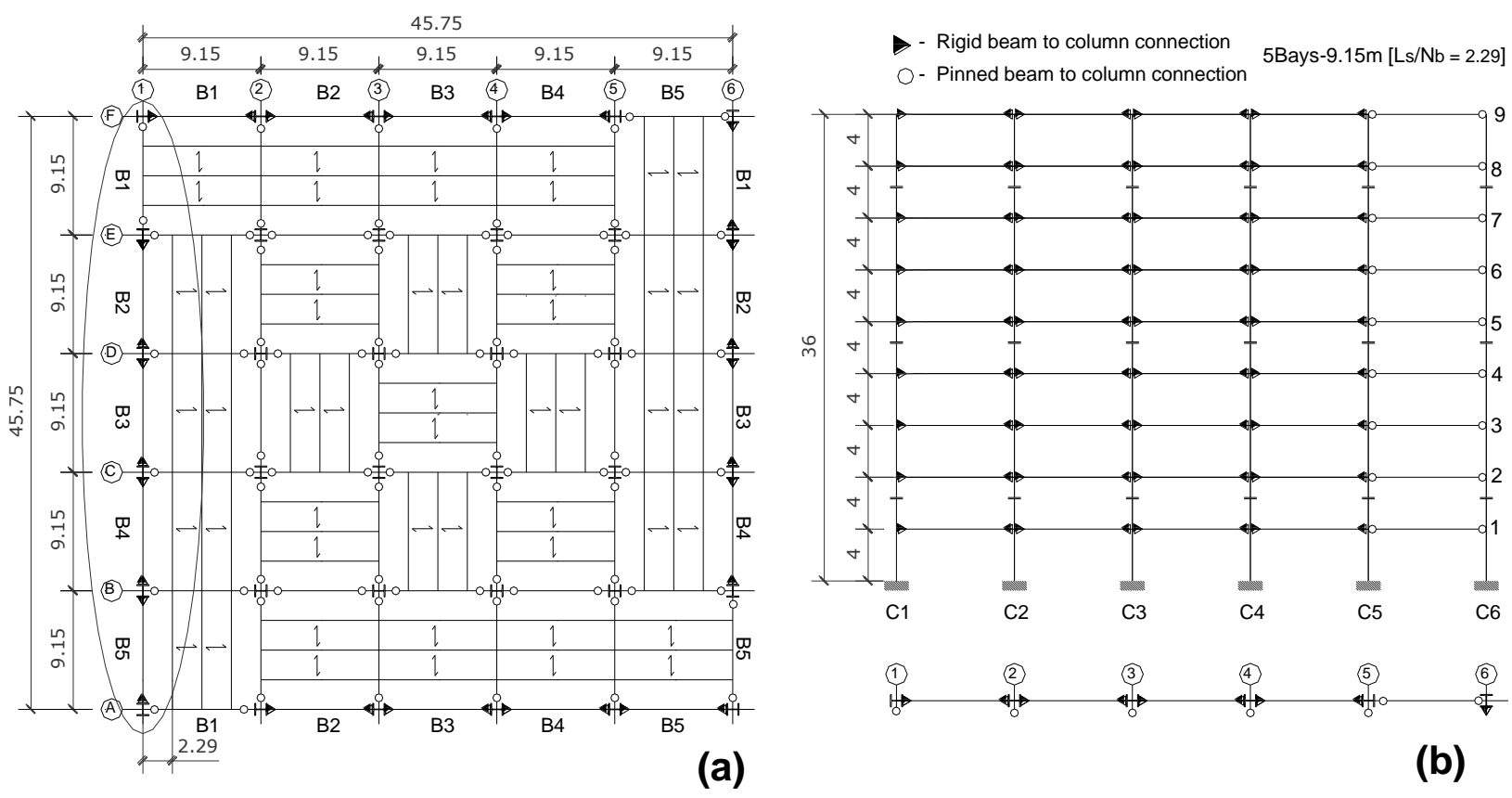

(a)

(b)

Figure 4. (a) Typical floor plan of 5 bays perimeter MRFs; and (b) perimeter frame elevation (in meters) 
In Table 1, the adopted cases with the assumed parameters, such as the number of bays, behaviour factors and drift limitations are summarized, concluding the 144 cases to be designed, analyzed through a modal response spectrum procedure and pushover analysis with a consequent elaboration of the results.

Table 1. Analyzed cases for 9, 7, and 5 Storey frames

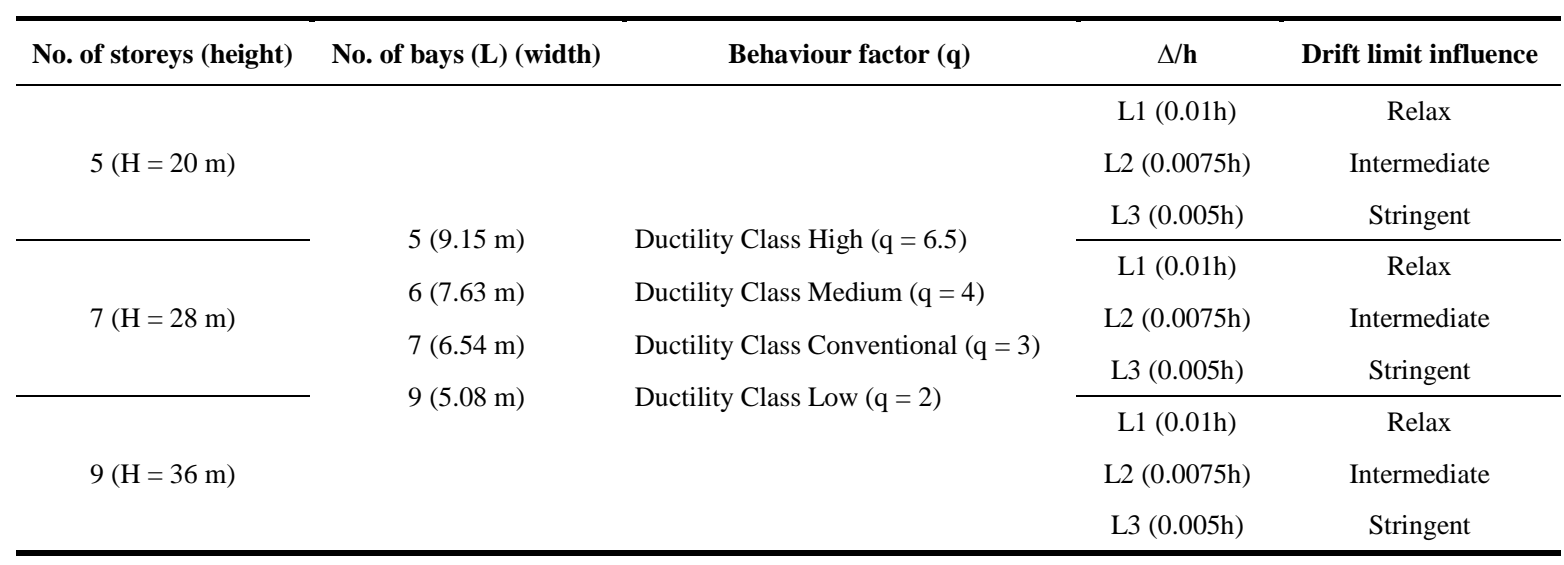

Vertical loads acting on the frames are evaluated according to Eurocode 0 and Eurocode 1, provided as a result of which total gravity loading (structural and non-structural) equal $4.6 \mathrm{kN} / \mathrm{m}^{2}$ for roof and $7.8 \mathrm{kN} / \mathrm{m}^{2}$ for the typical floor; these include imposed load of $0.4 \mathrm{kN} / \mathrm{m}^{2}$ and $3.0 \mathrm{kN} / \mathrm{m}^{2}$ for roof and typical floor, respectively. The secondary beams are assumed simply supported with a bay width equals $2.29 \mathrm{~m}$ and oriented for an optimized grid of the building. All the framing members are designed using EN 10025-2 S275 grade structural steel. The flooring system is composed of a COMFLOR-46 system [21], using A252 mesh, and comprises $145 \mathrm{~mm}$ thick concrete slab with $0.9 \mathrm{~mm}$ thick steel sheeting. The calculated masses are $589 \mathrm{kN}-\mathrm{sec}^{2} / \mathrm{m}$ for a typical floor, $491 \mathrm{kN}-\mathrm{sec}^{2} / \mathrm{m}$ for a roof; therefore, masses on each frame for 9, 7, and 5 storeys are 5203, 4025, and $2847 \mathrm{kN}$-sec $2 / \mathrm{m}$, respectively. The frames are designed according to EC8 with $\mathrm{q}$ factors $(\mathrm{q}=6.5,4,3$ and 2) using general-purpose civil engineering software SAP 2000 [22], considering type $\mathrm{C}$ soil stratigraphic profile (dense sand or gravel or stiff soil), important class II $(\gamma \mathrm{I}=1.0)$, type 1 elastic response spectrum and $0.25 \mathrm{~g}$ peak ground acceleration. It is also important to underline that the 1.6 torsional amplification factor, as described by EC8, is considered (as the analysis is performed using two planner models, so the torsional effect is determined by doubling the accidental eccentricity). Therefore, the assumed PGA is amplified by a torsion factor that equals 1.6 (resulting in an overall PGA equals $0.4 \mathrm{~g}$ ). Each frame is a perimeter frame, and to have symmetrically loaded frames with symmetrically oriented profiles, and each frame has a pinned connection to the corner bay. The material properties for the adopted steel grade (EN 10025-2 S275) is having a unit density $(\rho)=76.9$ $\mathrm{kN} / \mathrm{m}^{3}$, Poisson's ratio $(v)=0.3$, modulus of elasticity $(\mathrm{E}$ in $\mathrm{MPa})=2.10 \mathrm{E}+05$, yield stress $($ fy in $\mathrm{MPa})=275$, ultimate stress $(\mathrm{fu}$ in $\mathrm{MPa})=275$, expected yield stress $($ fye in $\mathrm{MPa})=302.5$ and expected ultimate stress $(\mathrm{fu}$ in $\mathrm{MPa})=473$ [23-26].

\section{Modelling and Acceptance Criteria}

A two-dimensional model of each frame is developed in SAP 2000 for nonlinear analysis. FEMA 356 [27, 28] acceptance criterion is adopted in the following cases; triangular load distribution is considered being more conservative in predicting the ultimate capacity of the structure. Frame elements are modelled as a line element having linearly elastic properties (rigidly connected) with lumped plasticity by defining plastic hinges at both ends of beams and columns, as shown in Figure 5. The modelling parameters and the acceptance criteria for nonlinear procedures for structural steel components, according to FEMA 356, are illustrated in Table 2.

The generalized force-displacement characteristic of a non-degrading frame element (or hinge properties) is defined according to SAP 2000. For nonlinear static procedures, the recoverable rotation may be estimated using the initial stiffness path as the unloading path. Alternatively, the yield rotation can be predetermined using conventional structural mechanics concepts as defined by FEMA 356. The P-D effect has been incorporated in the SAP 2000 analysis models. 


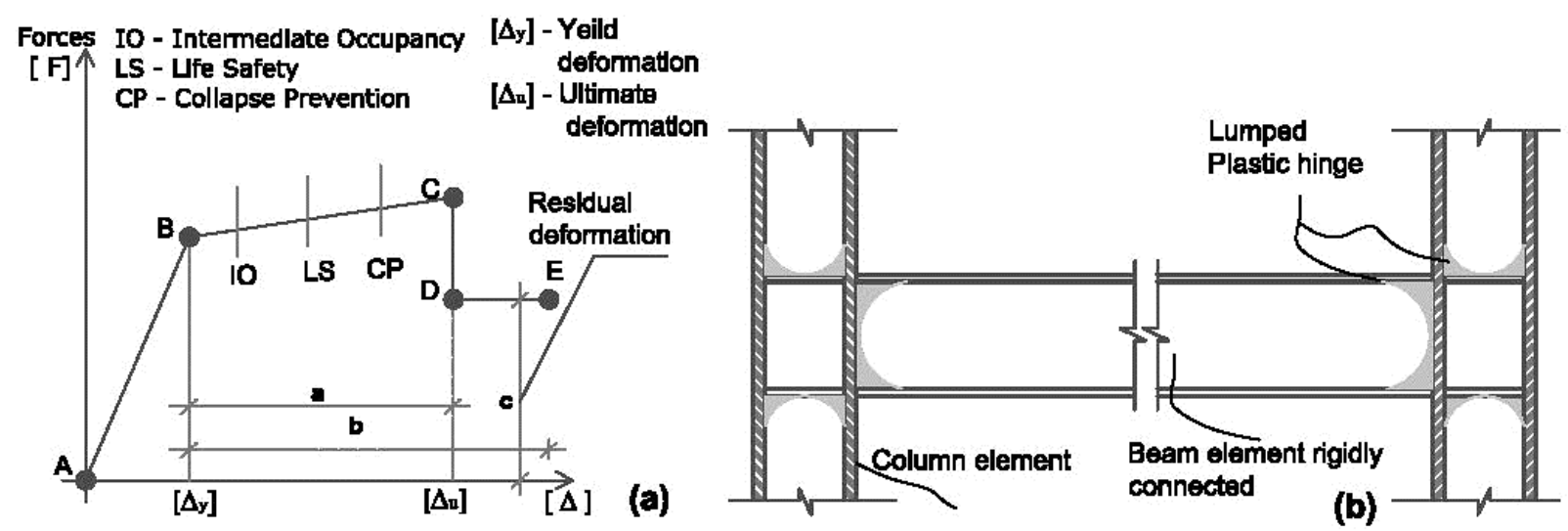

Figure 5. (a) Generalized force-deformation curve; and (b) Lumped plasticity model for frame element

Table 2. FEMA 356 modelling parameters and acceptance criteria for structural steel components

\begin{tabular}{|c|c|c|c|c|c|c|c|c|}
\hline \multirow{4}{*}{ Component/Action } & \multicolumn{3}{|c|}{ Modelling parameters } & \multirow{2}{*}{\multicolumn{5}{|c|}{$\begin{array}{c}\text { Acceptance criteria } \\
\text { Plastic rotation angle (radians) }\end{array}$}} \\
\hline & \multirow{2}{*}{\multicolumn{2}{|c|}{$\begin{array}{l}\text { Plastic rotation } \\
\text { angle (radians) }\end{array}$}} & \multirow{3}{*}{$\begin{array}{c}\begin{array}{c}\text { Residual } \\
\text { strength ratio }\end{array} \\
\text { (c) }\end{array}$} & & & & & \\
\hline & & & & \multirow{2}{*}{ IO } & \multicolumn{2}{|c|}{ Primary } & \multicolumn{2}{|c|}{ Secondary } \\
\hline & (a) & (b) & & & $\mathbf{L S}$ & $\mathbf{C P}$ & $\mathbf{L S}$ & $\mathbf{C P}$ \\
\hline \multicolumn{9}{|l|}{ Beam-flexure } \\
\hline a. $\frac{b_{f}}{2 t_{f}} \leq \frac{52}{\sqrt{F_{y e}}}$ and $\frac{h}{t_{w}} \leq \frac{418}{\sqrt{F_{y e}}}$ & $9 \theta_{\mathrm{y}}$ & $11 \theta_{\mathrm{y}}$ & 0.6 & $1 \theta_{\mathrm{y}}$ & $6 \theta_{\mathrm{y}}$ & $8 \theta_{\mathrm{y}}$ & $9 \theta_{\mathrm{y}}$ & $11 \theta_{\mathrm{y}}$ \\
\hline b. $\frac{b_{f}}{2 t_{f}} \leq \frac{65}{\sqrt{F_{y e}}}$ or $\frac{h}{t_{w}}>\frac{640}{\sqrt{F_{y e}}}$ & $4 \theta_{\mathrm{y}}$ & $6 \theta_{\mathrm{y}}$ & 0.2 & $0.25 \theta_{\mathrm{y}}$ & $2 \theta_{\mathrm{y}}$ & $3 \theta_{\mathrm{y}}$ & $3 \theta_{\mathrm{y}}$ & $4 \theta_{\mathrm{y}}$ \\
\hline c. Other & \multicolumn{8}{|c|}{$\begin{array}{l}\text { Linear interpolation between the values on lines } a \text { and } b \text { for both flange slenderness shall be } \\
\text { performed, and the lowest resulting value shall be used }\end{array}$} \\
\hline \multicolumn{9}{|l|}{ Column-flexure } \\
\hline \multicolumn{9}{|l|}{ For $\mathrm{P} / \mathrm{P}_{\mathrm{cl}}<0.20$} \\
\hline a. $\frac{b_{f}}{2 t_{f}} \leq \frac{52}{\sqrt{F_{y e}}}$ and $\frac{h}{t_{w}} \leq \frac{300}{\sqrt{F_{y e}}}$ & $9 \theta_{\mathrm{y}}$ & $11 \theta_{\mathrm{y}}$ & 0.6 & $1 \theta_{\mathrm{y}}$ & $6 \theta_{\mathrm{y}}$ & $8 \theta_{\mathrm{y}}$ & $9 \theta_{\mathrm{y}}$ & $11 \theta_{\mathrm{y}}$ \\
\hline b. $\frac{b_{f}}{2 t_{f}} \geq \frac{65}{\sqrt{F_{y e}}}$ or $\frac{h}{t_{w}} \geq \frac{460}{\sqrt{F_{y e}}}$ & $4 \theta_{\mathrm{y}}$ & $6 \theta_{\mathrm{y}}$ & 0.2 & $0.25 \theta_{\mathrm{y}}$ & $2 \theta_{\mathrm{y}}$ & $3 \theta_{\mathrm{y}}$ & $3 \theta_{\mathrm{y}}$ & $4 \theta_{\mathrm{y}}$ \\
\hline c. Other & \multicolumn{8}{|c|}{$\begin{array}{l}\text { Linear interpolation between the values on lines } a \text { and } b \text { for both flange slenderness shall be } \\
\text { performed, and the lowest resulting value shall be used }\end{array}$} \\
\hline \multicolumn{9}{|l|}{ For $0.20<\mathrm{P} / \mathrm{Pcl}<0.50$} \\
\hline a. $\frac{b_{f}}{2 t_{f}} \leq \frac{52}{\sqrt{F_{y e}}}$ and $\frac{h}{t_{w}} \leq \frac{260}{\sqrt{F_{y e}}}$ & ---3 & ---4 & 0.2 & $0.25 \theta_{\mathrm{y}}$ & ---5 & ---3 & ---6 & ---4 \\
\hline b. $\frac{b_{f}}{2 t_{f}} \geq \frac{65}{\sqrt{F_{y e}}}$ or $\frac{h}{t_{w}} \geq \frac{400}{\sqrt{F_{y e}}}$ & $1 \theta_{\mathrm{y}}$ & $1.5 \theta_{\mathrm{y}}$ & 0.2 & $0.25 \theta_{\mathrm{y}}$ & $0.5 \theta_{\mathrm{y}}$ & $0.8 \theta_{\mathrm{y}}$ & $1.2 \theta_{\mathrm{y}}$ & $1.2 \theta_{\mathrm{y}}$ \\
\hline c. Other & \multicolumn{8}{|c|}{$\begin{array}{l}\text { Linear interpolation between the values on lines } a \text { and } b \text { for both flange slenderness shall be } \\
\text { performed, and the lowest resulting value shall be used }\end{array}$} \\
\hline $\begin{array}{l}\text { 3. } \text { Plastic rotation }=11\left(1-1.7 \frac{P}{P_{C L}}\right) \\
\text { 5. Plastic rotation }=8\left(1-1.7 \frac{P}{P_{C L}}\right)\end{array}$ & lastic ro & $\begin{array}{l}7(1-1 \\
(1-1)\end{array}$ & $\theta_{y}$ & & & & & \\
\hline
\end{tabular}

Notations: h: overall depth of the profile, br: flange width, tf: flange thickness, tw: web thickness, Fye: expected yield strength of the material,

$\theta_{\mathrm{y}}$ : yield rotation, $\mathrm{P}$ : axial force in the member computed from nonlinear dynamic analysis, $\mathrm{P}_{\mathrm{CL}}$ : lower-bound compressive strength of the column.

\section{Nonlinear Analysis and Results}

Several parameters (such as ductility, redundancy, overstrength and behaviour factors) implemented in the seismic codes are defined here. The behaviour factor acquired from results is assessed for all the studied cases. Furthermore, as for a medium and long period, the "equal displacement rule" implies, as shown in Figure 5b. Therefore the main factors affecting the structural behaviour under seismic excitation can be obtained from pushover analysis, as shown in Figure 6a. 


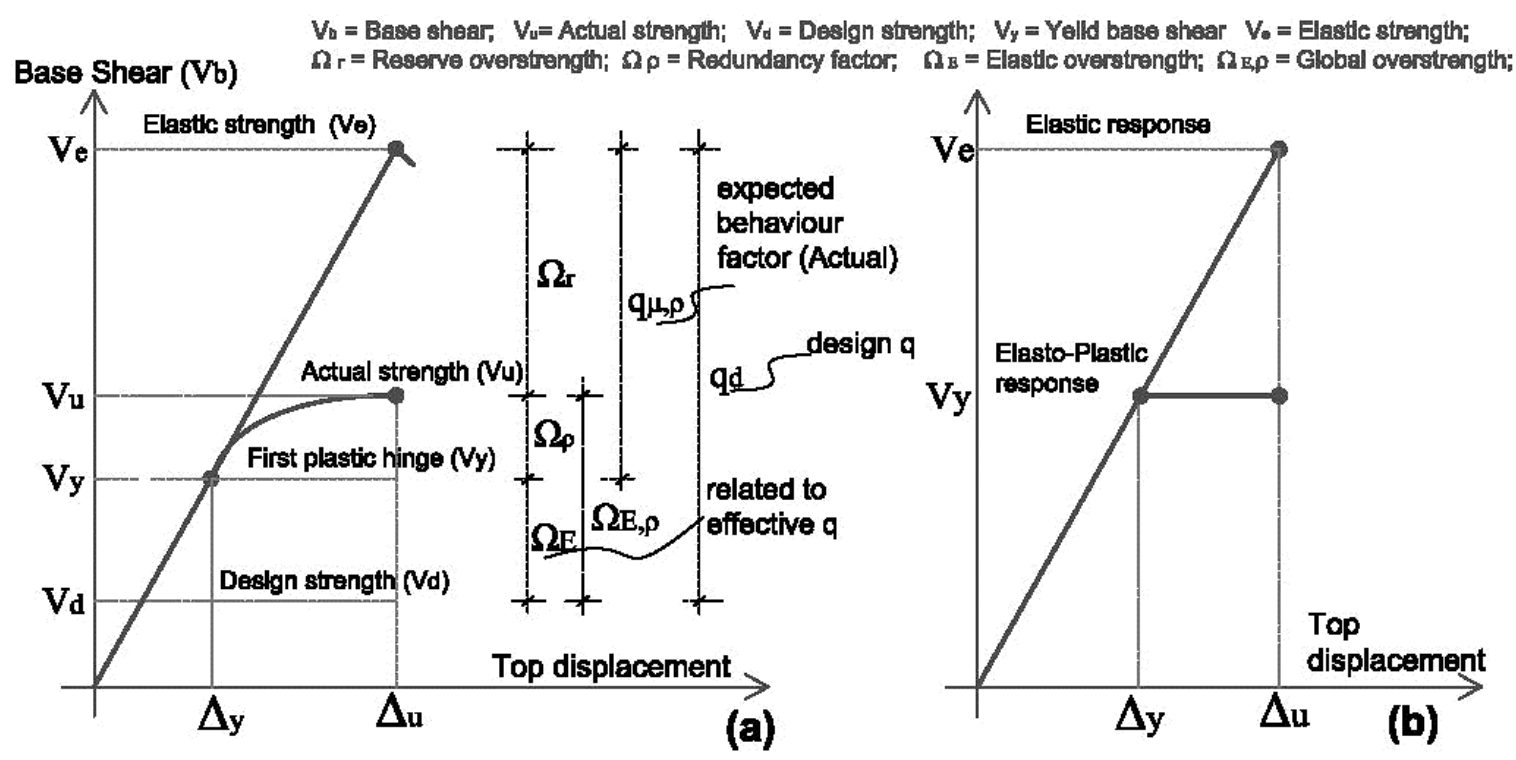

Figure 6. (a)Nomenclature of the factors; and (b) Equal displacement approximation

Ductility reduction factor $\left(\mathbf{q}_{\mu, \rho}\right)$ is the ratio of "the elastic base shear $\left(\mathrm{V}_{\mathrm{e}}\right)$ " to "the base shear obtained at the arrival of the first plastic hinge $\left(\mathrm{V}_{\mathrm{y}}\right)$ " as shown in Equation 2, it can also be termed as common behaviour factor.

$q_{\mu, \rho}=\frac{V_{e}}{V_{y}}$

Redundancy factor $\left(\Omega_{\rho}\right)$ is the overstrength given by the redistribution of the plastic hinges; it is the ratio of "the ultimate base shear $\left(\mathrm{V}_{\mathrm{u}}\right)$ obtained from pushover analysis" to "the base shear obtained at the arrival of the first plastic hinge $\left(\mathrm{V}_{\mathrm{y}}\right)$ " defined by Equation 3. Redundancy exists when multiple elements must yield or fail before a complete collapse mechanism forms. Structures possessing low inherent redundancy are required to be stronger and more resistant to damage, and therefore seismic design forces are amplified. Therefore, it is usually assumed that a structure with more considerable global ductility exhibits high redundancy and vice versa.

$q_{\mu, \rho}=\frac{V_{e}}{V_{y}}$

Elastic overstrength factor $\left(\Omega_{\mathbf{E}}\right)$ is the allowable stress reduction factor and is given by "the ratio of "the base shear corresponding to the arrival of the first plastic hinge $\left(\mathrm{V}_{\mathrm{y}}\right)$ " to "the design base shear calculated from the prescribed code $\left(\mathrm{V}_{\mathrm{d}}\right)^{\prime}$ given by Equation 4 . As an ideal scenario in the design, the elastic overstrength $\left(\Omega_{\mathrm{E}}\right)$ might be unity. Since the structural capacity must not be less than the design force, $\Omega_{\mathrm{E}}$ is always at least 1 .

$\Omega_{E}=\frac{V_{y}}{V_{d}}$

Global overstrength factor $\left(\Omega_{\mathrm{E}, \rho}\right)$ is given by the ratio of "the ultimate base shear $\left(\mathrm{V}_{\mathrm{u}}\right)$ " to "the design base shear calculated from the prescribed code $\left(\mathrm{V}_{\mathrm{d}}\right)^{\text {"; }}$; it corresponds to the product of redundancy factor and elastic overstrength, evaluated from Equation 5.

$\Omega_{E, \rho}=\Omega_{E} \times \Omega_{\rho}=\left(\frac{V_{y}}{V_{d}}\right) \times\left(\frac{V_{u}}{V_{y}}\right)=\frac{V_{u}}{V_{d}}$

Reserve ductility $\left(\mathbf{q}_{\mu}\right)$ is the ratio of "the elastic base shear $\left(\mathrm{V}_{\mathrm{e}}\right)^{\text {" to }}$ "the ultimate base shear $\left(\mathrm{V}_{\mathrm{u}}\right)$ " as given in Equation 6.

$q_{u}=\left(\frac{V_{e}}{V_{u}}\right)$

The behaviour factor $\left(\mathbf{q}_{\mathbf{d}}\right)$ is given by the ratio of "the elastic base shear $\left(\mathrm{V}_{\mathrm{e}}\right)$ " to "design base shear calculated from the prescribed code $\left(\mathrm{V}_{\mathrm{d}}\right)$ ", it is merely the product of the elastic overstrength, redundancy factor, and reserve ductility defined by Equation 7. 


$$
\begin{aligned}
& q_{d}=\Omega_{E} \times \Omega_{\rho} \times q_{\mu}=\left(\frac{V_{y}}{V_{d}}\right) \times\left(\frac{V_{u}}{V_{y}}\right) \times\left(\frac{V_{e}}{V_{u}}\right)=\frac{V_{e}}{V_{d}} \text { or } q_{d}=\left(\frac{\Delta_{u}}{\Delta_{y}}\right) \\
& q_{\mu}=\frac{V_{e}}{V_{u}}=\frac{q_{d}}{\Omega_{E, \rho}} \\
& q_{\mu, \rho}=\frac{V_{e}}{V_{y}}=q_{u} \times \Omega_{\rho}
\end{aligned}
$$

\section{Ductility and Behaviour Factor}

The structural ductility $\left(\Delta_{\psi} / \Delta_{\mathrm{Y}}\right)$, also termed here displacement ductility factors of the frames are evaluated and provided in this section, see Figure 7 (for 5 and 6 bays), and Figure 8 (for 7 and 9 bays). Such ductility factors represent the overall behaviour and performance of the designed frames.
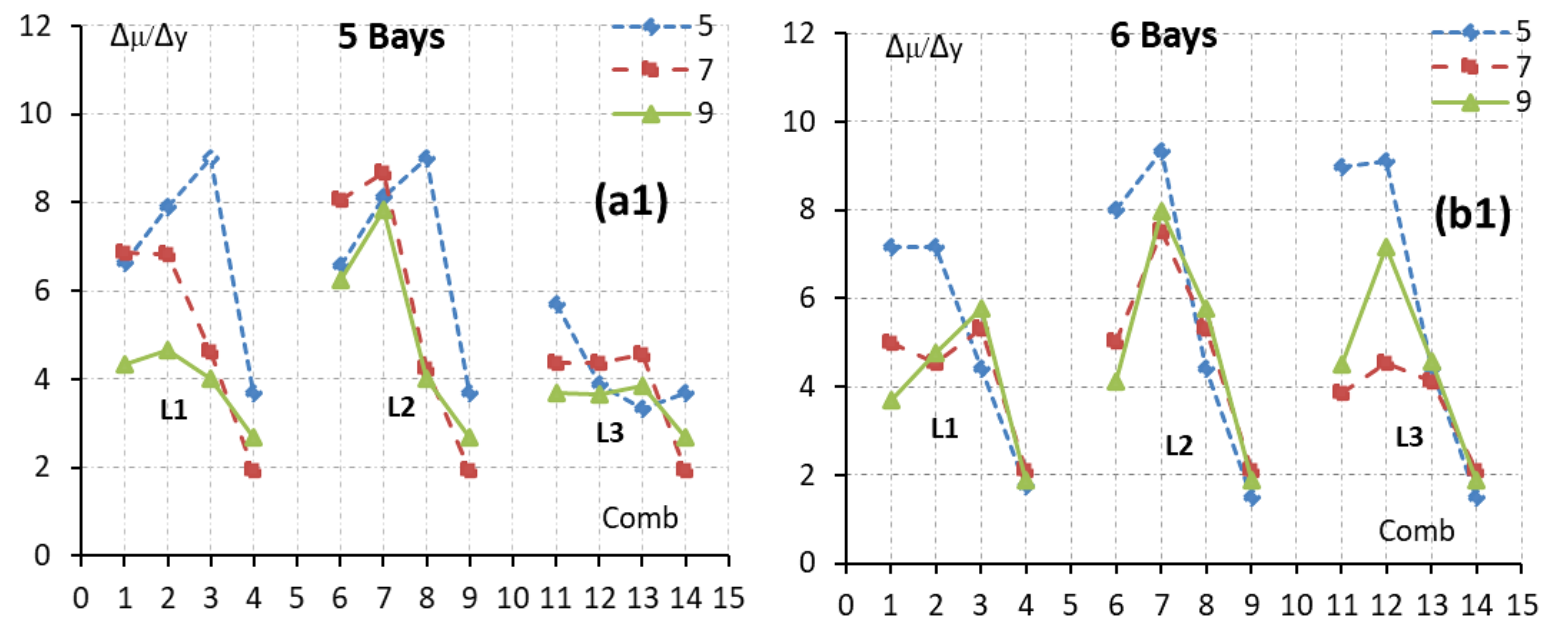

Figure 7. Ductility factors for (a1) 5 bays; and (b1) 6 bays

It is evident that when $q$ equals 2.0 (DCL), the ductility ratio obtained from the nonlinear analysis is about 2.0. It has been observed that this ratio decreases as the drift limit vary from relaxing to the more stringent one. It seems evident that the drift limitations greatly influence the ductility class (especially on DCH.).
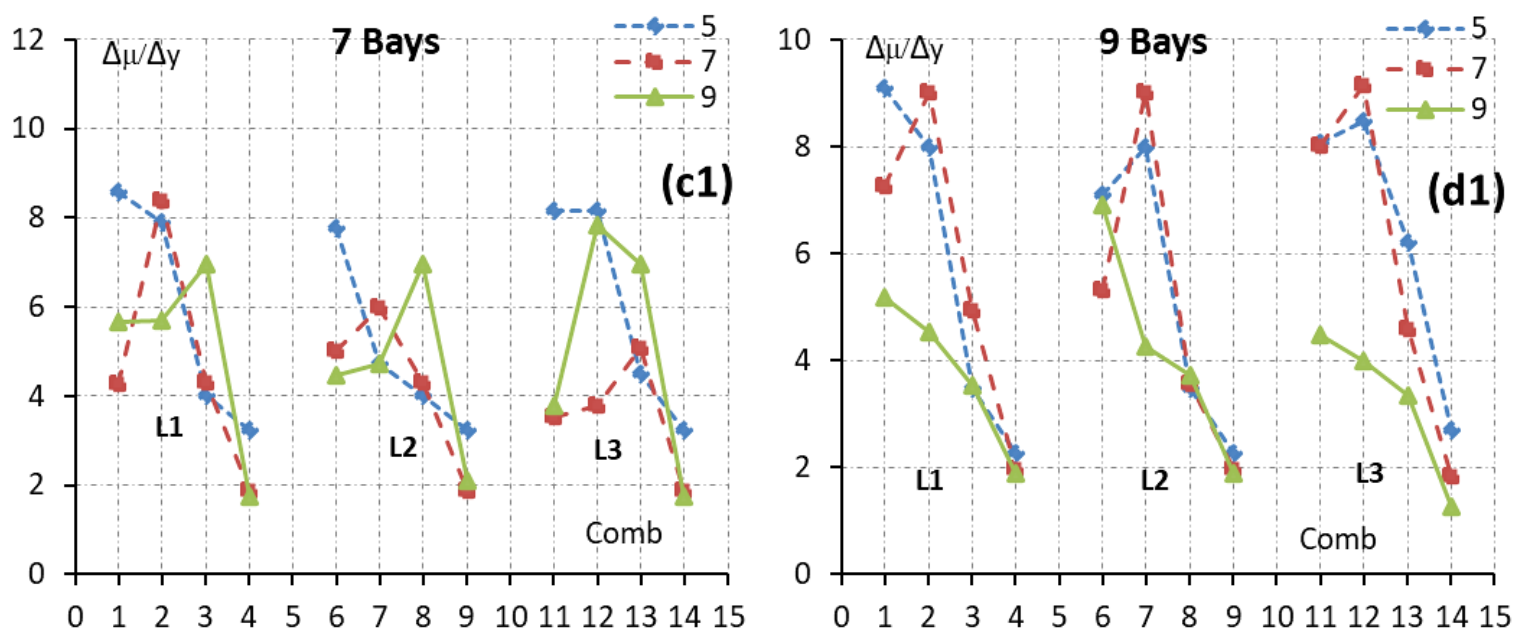

Figure 8. Ductility factors for (c1) 7 bays; and (d1) 9 bays

The obtained ductility in the case of DCH, when q equals 6.5 , is generally less than the ones obtained from DCM, with q equals 4.0. This is due to the drift limits of the code being quite strict that when these limits are satisfied the capacity design rules are disturbed and the assumed ductility of the frames might not be achieved in reality. Therefore, drift limitation dictates the design which is due to the spectrum's reduction to the same level for all ductility classes. In 
conclusion, it is worth mentioning that all the combinations related to DCM behave better than the rest of the studied ductility classes.
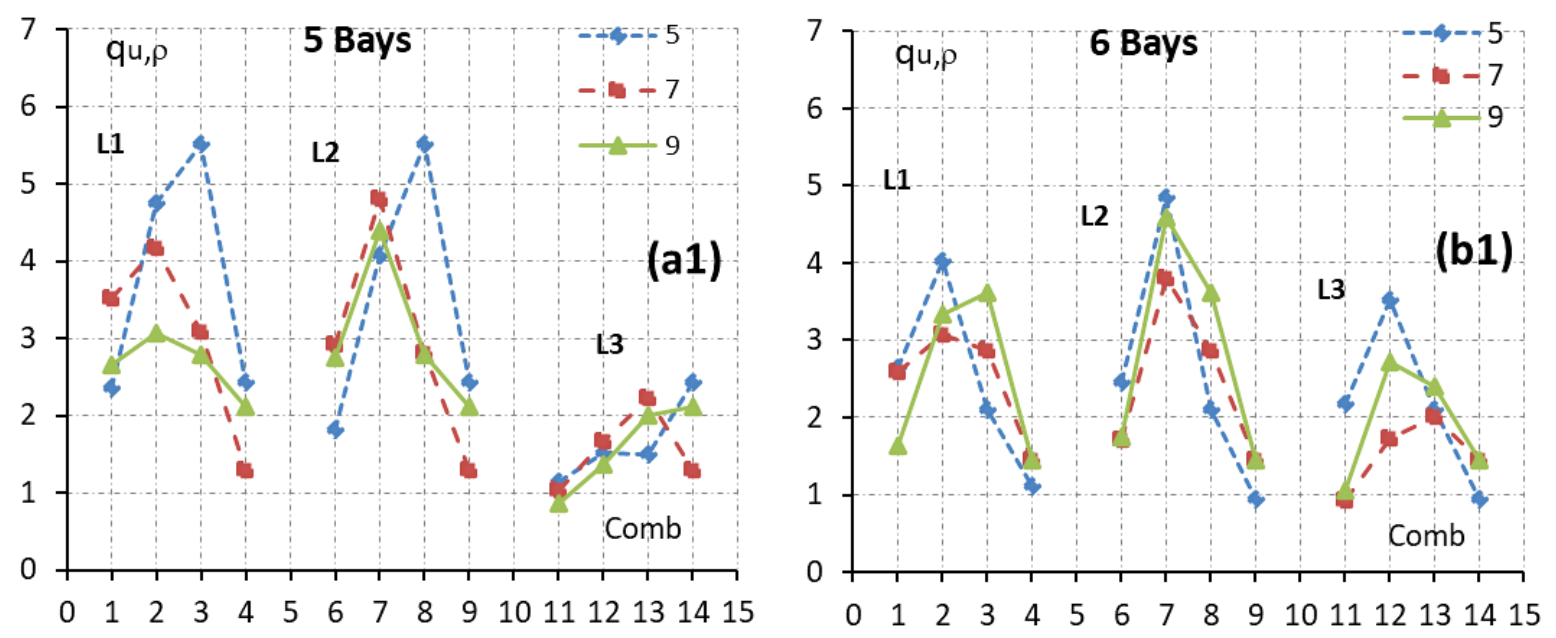

Figure 9. Behaviour factors for (a1) 5 bays; and (b1) 6 bays
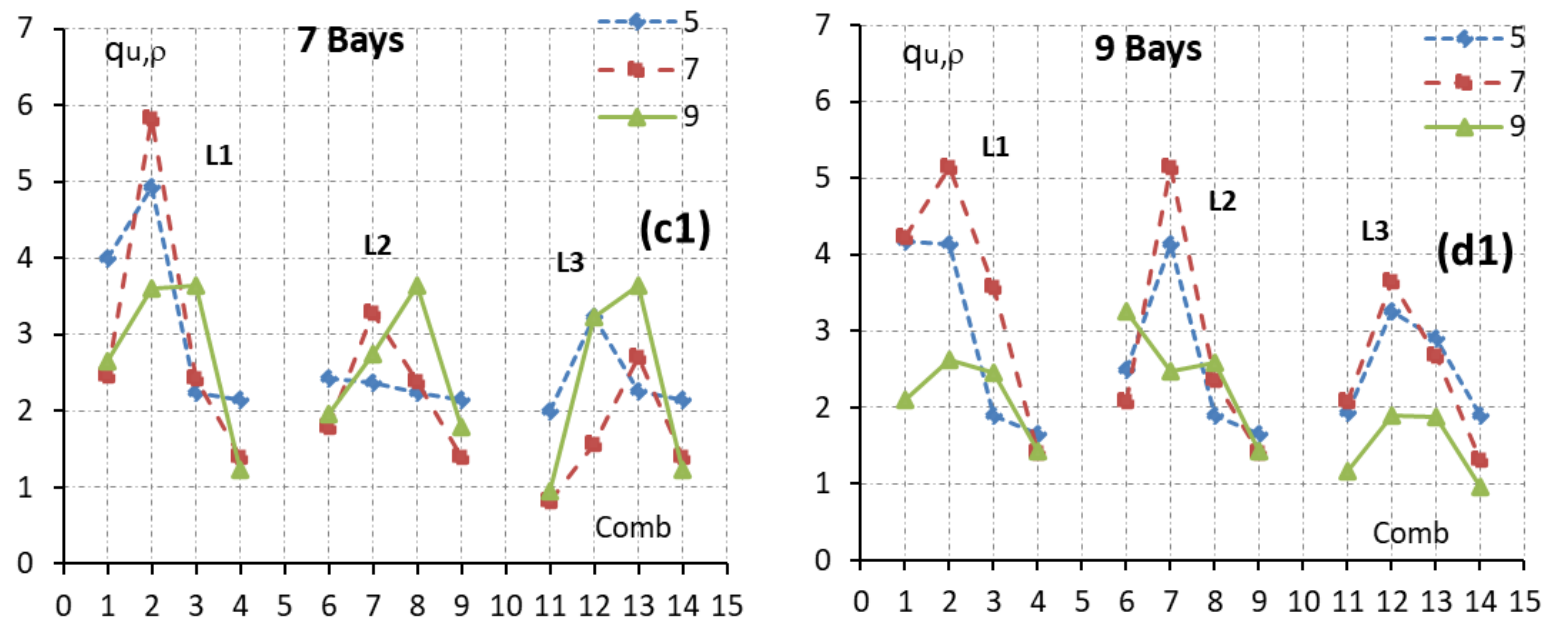

Figure 10. Behaviour factors for (c1) 7 bays; and (d1) 9 bays

Furthermore, the behaviour factor $\left(\mathrm{q}_{\mathrm{u}, \rho}\right)$ evaluated given by Equation 9 from the pushover curves for the frames are summarised here. These are shown in Figure 9 (for 5 and 6 bays) and in Figure 10 (for 7 and 9 bays). These graphs demonstrate the influence of $\mathrm{q}$ factors that the structure processes. All the combinations with $q=4.0$ give higher value except for 9 storeys frames where generally strengths govern the design. The use of different ductility classes with drift limit L3 is not compatible as can be observed from Figures 9 and 10. This drift limit is quite strict, generally for structures with quite brittle curtain walls. It is therefore evident that the use of this limit for DCH might not guarantee ductile or optimum design solution, therefore necessitates that seismic codes provide clear recommendation for the designer for considering a ductility class with a compatible value of drift limits for ductile as well as an optimum design solution.

\section{Conclusions}

The paper had dealt with steel moment-resisting frames of 5, 7, and 9 storeys with 4.0m inter-story height. Four bays of 5, 6, 7, and 9 having span-length of $9.15 \mathrm{~m}, 7.63 \mathrm{~m}, 6.54 \mathrm{~m}, 5.08 \mathrm{~m}$, respectively, have been considered. Four behaviour factors $(6.5,4,3$, and 2$)$ are assumed considering three drift limits $(\mathrm{L} 1=0.01 \mathrm{~h}, \mathrm{~L} 2=0.075 \mathrm{~h}$, and $\mathrm{L} 3=0.05 \mathrm{~h})$ as per Eurocode 8, concluding 144 cases. Each case has been designed using Eurocodes provisions, analyzed using nonlinear FEMA 356 acceptance criteria. Several interesting conclusions are drawn, such as:

- When drift limitation governs the design, the behaviour factor is not optimally utilized and therefore leads to an uneconomical design situation. The rationale behind this being the targeted ductility cannot be achieved at the end of the design. 
- In the Ductility Class High "DCH," the drift criterion governs the design, especially in the case of drift limit "L2" $(0.0075 \mathrm{~h})$ and "L3" $(0.005 \mathrm{~h})$, therefore showing that it is not useful to adopt high ductility when drift limits "L2" or "L3" are used. Hence, it is suggested to use "DCH" only when the drift limit "L1" (0.01h) is considered otherwise; damageability criteria dictate the design.

- In the Ductility Class Medium "DCM," the q factor is optimally used when the drift limit "L1" is adopted in the design, as the strengths govern the design. Instead, for the drift limit "L2," there is a question mark regarding the optimum use of q factor, but it is found that for the drift limit "L3," the behaviour factor is not used optimally, and therefore, it is inconvenient. Hence, it is observed that when dealing with the drift limit "L3", it is uneconomical to use the ductility class of Eurocode 8.

- The Drift limit "L3" is compatible with q equals 3.0; therefore, it is suggested to use it when the drift limit "L3" needs to be used in the design.

- In the Ductility Class Low "DCL" (elastic analysis), the frames are designed following only the Eurocode 3 criteria with the exclusion of Eurocode 8, here all the drift limits ("L1", "L2" and "L3") are almost inevitably fulfilled. It leads to a state that the code specified drift limit, mostly "L3," is directly related to the elastic analysis and can be satisfied if the elastic analysis is implemented.

Given the above, it is concluded that the use of the behaviour factors is related to the adopted drift limits. Hence, it is suggested to have a relationship between the damageability and ductility before the commencement of any steel moment-resisting frame design.

\section{Acknowledgements}

The author positively acknowledges the guidance of Prof De Matteis and Prof Antonio De Luca.

\section{Conflicts of Interest}

The authors declare no conflict of interest.

\section{Nomenclature}

$\begin{array}{ll}\text { ad } & \text { Design acceleration } \\ \delta \mathrm{d} & \text { Maximum displacement evaluated by applying } a d \\ \text { wy } & \text { Elastic strain energy stored by the system in the yield state } \\ \text { wu } & \text { Total energy stored and dissipated up to structural failure } \\ \Omega_{0} & \text { System overstrength factor } \\ \mathrm{f}_{\mathrm{y}} & \text { Nominal yield strength } \\ \gamma_{\mathrm{ov}} & \text { Material overstrength } \\ \rho & \text { Redundancy factor } \\ \Omega_{\mathrm{o}} & \text { Overstrength factor } \\ \mathrm{P}_{\mathrm{uc}} & \text { Compressive strength using LRFD load combinations } \\ \mathrm{F}_{\mathrm{yb}} & \text { Specified minimum yield stress of the beam } \\ \mathrm{F}_{\mathrm{yc}} & \text { Specified minimum yield stress of column } \\ \mathrm{R}_{\mathrm{y}} & \text { Ratio of expected yield stress to specified minimum yield stress } \\ \mathrm{Z} & \text { Plastic section modulus } \\ \mathrm{F}_{\mathrm{ye}} & \text { Yield stress of the material } \\ \theta_{\mathrm{y}} & \text { Yield rotation } \\ \mathrm{P} & \text { Axial force in the member computed from nonlinear dynamic analyses } \\ \mathrm{PCL} & \text { Lower bound compressive strength of the column } \\ \varepsilon & \text { Strain of steel material }\end{array}$

$\begin{array}{ll}\sigma & \text { Stress of steel material } \\ \varepsilon_{\mathrm{u}} & \text { Ultimate strain } \\ \Delta_{\mu} / \Delta_{\mathrm{y}} & \text { Ductility factor } \\ \mathrm{q}_{\mu} & \text { Reserve overstrength } \\ \mathrm{q}_{\mathrm{u}, \rho} & \text { Actual behaviour factor } \\ \Omega_{\mathrm{calc}} & \text { Calculated overstrength } \\ \Omega_{\mathrm{E}} & \text { Elastic overstrength } \\ \Omega_{\rho} & \text { Redundancy factor } \\ \Omega_{\mathrm{E}, \rho} & \text { Global overstrength } \\ \alpha_{\mathrm{CR}} & \text { Alpha critical } \\ \mathrm{T} & \text { Fundamental period (in sec) } \\ \mathrm{L} 2 & \text { Drift limit (0.0075h) } \\ \mathrm{L} 3 & \text { Drift limit (0.005h) } \\ \text { L1 } & \text { Drift limit (0.01h) } \\ \text { DCH } & \text { Ductility Class High (q=6.5) } \\ \text { DCM } & \text { Ductility Class Medium (q=4) } \\ \text { DCC } & \text { Ductility Class Conventional (q=3) } \\ \text { DCL } & \text { Ductility Class Low (q=2) }\end{array}$

\section{References}

[1] Uang, Chia-Ming. "Establishing $R$ (or $R_{w}$ ) and $C_{d}$ factors for building seismic provisions." Journal of structural Engineering 117, no. 1 (1991): 19-28. doi:10.1061/(asce)0733-9445(1991)117:1(19).

[2] Humar, J L, and M A Rahgozar. "Application of Uniform Hazard Spectra in Seismic Design of Multistorey Buildings." Canadian Journal of Civil Engineering 27, no. 3 (June 1, 2000): 563-580. doi:10.1139/199-045. 
[3] Dell'Aglio, Giuseppe, Rosario Montuori, Elide Nastri, and Vincenzo Piluso. "Consideration of Second-Order Effects on Plastic Design of Steel Moment Resisting Frames.” Bulletin of Earthquake Engineering 17, no. 6 (February 12, 2019): 3041-3070. doi:10.1007/s10518-019-00573-9.

[4] Kappos, A.J. "Evaluation of Behaviour Factors on the Basis of Ductility and Overstrength Studies." Engineering Structures 21, no. 9 (September 1999): 823-835. doi:10.1016/s0141-0296(98)00050-9.

[5] Castiglioni, Carlo A., and Alessandra Zambrano. "Determination of the Behaviour Factor of Steel Moment-Resisting (MR) Frames by a Damage Accumulation Approach.” Journal of Constructional Steel Research 66, no. 5 (May 2010): $723-735$. doi:10.1016/j.jcsr.2009.11.002.

[6] Sanchez-Ricart, L., and A. Plumier. "Parametric Study of Ductile Moment-Resisting Steel Frames: A First Step Towards Eurocode 8 Calibration.” Earthquake Engineering \& Structural Dynamics 37, no. 7 (2008): 1135-1155. doi:10.1002/eqe.809.

[7] Fathi, M., F. Daneshjoo, and R.E. Melchers. "A Method for Determining the Behaviour Factor of Moment-Resisting Steel Frames with Semi-Rigid Connections." Engineering Structures 28, no. 4 (March 2006): 514-531. doi:10.1016/j.engstruct.2005.09.006.

[8] Gioncu, Victor, and Federico Mazzolani. Seismic design of steel structures. CRC Press, (2013).

[9] Elghazouli, A. Y. “Assessment of European Seismic Design Procedures for Steel Framed Structures.” Bulletin of Earthquake Engineering 8, no. 1 (May 28, 2009): 65-89. doi:10.1007/s10518-009-9125-6.

[10] Naqash, Muhammad Tayyab, Gianfranco De Matteis, and Antonio De Luca. "Seismic design of steel moment resisting frames (Mrfs)- European versus American practice." NED University Journal of Research 9, no. 2 (2012): 45-60.

[11] Newmark, Nathan M., and William J. Hall. "Seismic design criteria for nuclear reactor facilities." In Proceedings of the 4th World conference on Earthquake Engineering, vol. 4, (1969): 37-50.

[12] Mellati, Afshin. "Predicting Dynamic Capacity Curve of Elevated Water Tanks: A Pushover Procedure." Civil Engineering Journal 4, no. 11 (November 29, 2018): 2513. doi:10.28991/cej-03091177.

[13] Fajfar, Peter. “A Nonlinear Analysis Method for Performance-Based Seismic Design.” Earthquake Spectra 16, no. 3 (August 2000): 573-592. doi:10.1193/1.1586128.

[14] Miranda, Eduardo, and Vitelmo V. Bertero. "Evaluation of Strength Reduction Factors for Earthquake-Resistant Design." Earthquake Spectra 10, no. 2 (May 1994): 357-379. doi:10.1193/1.1585778.

[15] Karsaz, Kamran, and Seyed Vahid Razavi Tosee. "A Comparative Study on the Behavior of Steel Moment-Resisting Frames with Different Bracing Systems Based on a Response-Based Damage Index.” Civil Engineering Journal 4, no. 6 (July 4 , 2018): 1354. doi:10.28991/cej-0309178.

[16] UBC-97. Uniform Building Code-Volume 2. In International Conference of Building officials (1997).

[17] American Institute of Steel Construction (AISC). "Seismic Provisions for Structural Steel Buildings." Seismic Provisions for Structural Steel Buildings (2010).

[18] ASCE/SEI 7-16 "Minimum Design Loads and Associated Criteria for Buildings and Other Structures” (June 15, 2017$):$ 822. doi:10.1061/9780784414248.

[19] Breinlinger, F., Kunz, C., Loche, K., Niemann, H. J., Novák, B., Ruckenbrod, C., \& Schwind, W. "Eurocode 1-Actions on Structures.” Dictionary Geotechnical Engineering/Wörterbuch GeoTechnik (2014): 485-485. doi:10.1007/978-3-642-41714$6 \_51754$.

[20] BS EN 1993-1-1.de Construção, Associação Portuguesa. Design of Steel Structures: Eurocode 3: Design of Steel Structures, Part 1-1: General Rules and Rules for Buildings. John Wiley \& Sons, (2016).

[21] Composite Floor Decks, Composite Decking | Tata Steel. Available online: https://www.tatasteelconstruction.com/en_GB/Products/structural-buildings-and-bridges/Composite-floor-deck (accessed on 21 August 2020).

[22] Structural Software for Analysis and Design | SAP2000. Available online: https://www.csiamerica.com/products/sap2000 (accessed on 21 August 2020).

[23] Naqash, Muhammad Tayyab, and Ayed Alluqmani. "Codal Requirements Using Capacity Design Philosophy, and Their Applications in the Design of Steel Structures in Seismic Zones." Open Journal of Earthquake Research 07, no. 02 (2018): 88107. doi:10.4236/ojer.2018.72006.

[24] Naqash, M. T., Gianfranco De Matteis, and A. De Luca. "Effects of capacity design rules on seismic performance of steel moment resisting frames." In World Conference on Earthquake Engineering (WCEE), Lisbon Portugal. (2012). 
[25] Tayyab Naqash, Muhammad. "An Overview on the Seismic Design of Braced Frames." American Journal of Civil Engineering 2, no. 2 (2014): 41. doi:10.11648/j.ajce.20140202.15.

[26] Tayyab Naqash, Muhammad. "Inelastic Behavior of Steel Buildings in Seismic Zones.” Advances in Applied Sciences 3, no. 1 (2018): 1. doi:10.11648/j.aas.20180301.11.

[27] FEMA 356. FEMA 356 Prestandard. US Federal Emergency Management Agency, (2000).

[28] Hakim, R. A., M. S. Alama, and S. A. Ashour. "Seismic Assessment of RC Building According to ATC 40, FEMA 356 and FEMA 440.” Arabian Journal for Science and Engineering 39, no. 11 (October 4, 2014): 7691-7699. doi:10.1007/s13369-0141395-x. 